\title{
Landscape ecology, biogeography and GIS methods
}

\author{
Monika Böhm and Viorel D. Popescu
}

\subsection{Introduction}

\subsubsection{Landscape ecology, biogeography, and macroecology}

Landscape ecology examines "the effects of the spatial configuration of mosaics on a wide variety of ecological phenomena" (Wiens et al. 1993). Landscape composition and configuration across space has wide-ranging effects on species. It determines where the right climatic, elevational or soil conditions occur to suit the physiological requirements of a species (Kearney and Porter 2004). It also affects where a species can feed, breed, and how they can avoid mortality from predators or inter-species competition. In its simplest form, landscape ecology aims to examine the distribution of habitat and its effects on ecological processes (Lindenmayer et al. 2008).

Because habitat loss is the overriding cause of biodiversity loss, including in reptiles (Böhm et al. 2013), knowledge of habitat distribution across space, as well as changes through time, are essential to management and conservation initiatives. While landscape ecology research is often species- or landscape-specific, generalising patterns across landscapes and species is another important field gaining momentum in ecology and conservation. Biogeography and macroecology analyse patterns between species (e.g. species 
richness, range size, threat) and the environment over broad spatial (e.g. regional, continental, global) or temporal scales (e.g. evolutionary timescales).

This broad-scale view - as is also the case with landscape ecology - results from the realisation that looking at small-scale processes alone often fails to fully explain observed patterns in the abundance or distribution of species. The aim of broad-scale analyses is to find generalisations across larger spatial or temporal scales, a critical perspective in conservation, since it is impossible to study all landscapes and species to the detail required for their effective conservation. Other threats, especially climate change, are likely to exacerbate landscape and ecosystem changes (Thomas et al. 2004). Thus, general conclusions from broadly-observed patterns are often the primary focus of global conservation policy and decision-making, and can help steer conservation planning towards the most vulnerable species, landscapes, or ecosystems in the face of environmental change. In contrast, insights from landscape ecology studies focused on specific regions, species or communities are critical for informing management or conservation decisions at local and regional scales (e.g. habitat restoration or population augmentation).

Reptiles are still scarcely represented in landscape ecology, biogeography, and macroecology compared to other vertebrate taxa (Figure 22.1). Yet technological advances have brought about a wealth of spatial data, from locality data taken by global positioning systems (GPS) to high-resolution satellite imagery and aerial photography. Faster and more powerful computers are able to handle complex spatial analyses and store large datasets. Software developments for spatial analyses [i.e. Geographical Information Systems (GIS)] have produced a large suite of tools to manipulate and analyse data. Given these developments, we can become more spatially explicit in our problem-solving: why does a species occur in one place, but not another? Which environmental conditions are important to 
a species? What are the hotspots of species richness? Where should we focus protected areas and conservation funding?

In this chapter, we introduce recent developments in GIS, landscape ecology, macroecology and biogeography, and list important sources of data and applications that help to tackle complex biological and ecological questions spanning many spatial and temporal scales.

\subsubsection{Geographic Information Systems (GIS)}

A GIS is a family of software that allows us to visualize, store, manipulate, analyse and model spatial data (i.e. georeferenced data). Spatial data come in vector or raster format. Vector data include point data, lines, and polygons (e.g. coordinates, transect lines or habitat ranges, respectively; Figure 22.2). Vector data are associated with additional data attributes, which provide additional information such as the number of individuals sampled at a point locality, the name of a river or a road displayed as a line, or the type of habitat represented by a polygon.

Rasters are continuous matrices of grid cells, with each cell containing a single value summarising the landscape feature it represents (e.g. mean elevation, or a code defining the prevalent habitat type in the grid cell, such as 1 for tropical rain forest, 2 for agricultural lands, etc.). The spatial resolution of a raster is reflected in its grid cell size: finer grids with smaller grid cells (e.g. 1-100 $\mathrm{m}^{2}$ ) capture a high degree of spatial complexity and detail, while coarser grids, with larger cells (e.g. 1- $100 \mathrm{~km}^{2}$ ) provide a more generalised view of the landscape, at the cost of losing detail. Unlike vectors, rasters do not represent the exact boundaries of a spatial object, but their continuous nature allows us to carry out mathematical operations on cell values and model surfaces across space. 
Both raster and vector data relevant to ecology and conservation have become widely available and are, in many cases, open-source (see Sillero and Tarroso 2010). Similarly, there is a wide choice of GIS packages that allow these data to be stored, visualised, manipulated and analysed, often featuring graphical user interfaces to facilitate software use. While prices for commercial packages vary depending on the licenses acquired and functionalities included, there is an ever-increasing number of open-source GIS software available. Many of these allow users to develop their own functionalities that, in turn, may become available open-source (e.g. Quantum GIS and its plugin repository at http://plugins.qgis.org/plugins/). Additionally, tools to aid spatial data visualisation and analysis have also been developed for other software environments, most prominently $\mathrm{R}$, a freely-available environment for statistical computing (http://www.r-project.org/index.html). However, R may require the writing of scripts, and some understanding of programming languages is required.

\subsection{Landscape ecology concepts applied to reptile ecology and conservation}

\subsubsection{Landscape composition and configuration}

Landscapes can be perceived as mosaics of habitats with varying degrees of heterogeneity in their composition or configuration (e.g., continuous boreal forest with little variation in tree species composition vs. rural landscapes with many native and disturbed habitats).

Landscapes can also be defined more simply as patches of suitable habitat within a matrix of less suitable or unsuitable habitat. Habitat suitability varies across species, but it may also vary within species, for example with developmental stage, such as between juveniles and adults (e.g. Sand Lizards using microhabitats differently depending on age group; Stellatelli et al. 2013). The size and quality of available habitat patches in the landscape are intrinsically linked to species conservation as they affect population densities and persistence, and extinction risk (Hanski 1999, Lindenmayer et al. 2008). GIS can help delineate habitat 
patches, evaluate their size, shape, and connectivity, and, in doing so, aid conservation efforts. For example, rocky outcrops are vital habitats for species such as the New Zealand Grand Skink Oligosoma grande, a species of conservation concern (Gebauer et al. 2013, Harris et al. 2014). Recent studies defined the occurrence of such outcrops from aerial photography and GPS-captured occurrence records from field studies.

\subsubsection{Structural and functional connectivity}

Connectivity is the degree to which the landscape facilitates or impedes movement among habitat patches. Landscape connectivity can be structural/physical, defined by the spatial arrangement of patches, as well as functional, defined by the likelihood of movement of individuals among patches. Assessing the connectivity between habitat patches and the type and quality of the matrix of non-habitat is an important consideration in ecological and conservation studies of reptiles. GIS can be used to map and identify corridors connecting high suitability habitat patches or non-habitat matrices of varying quality. In its simplest form, we can estimate physical and structural connectivity using Euclidean (or straight-line) distance between patches. A simple measure of connectivity was proposed by Hanski (1999) and forms the basis of metapopulation theory - the dynamics of populations arranged in distinct habitat patches within a non-habitat matrix. Here,

$$
\text { connectivity }=\sum_{i=1}^{n} e^{-d_{i j}} A_{j}
$$

where $d$ is the distance between patch $i$ and patch $j$ and $A_{j}$ is the carrying capacity of patch $j$. Thus, this index takes into account distance between patches as well as patch size. Such an index may work well for measuring connectivity between populations or subpopulations confined to distinct landscape features (e.g., pools of water, discrete rocky outcrops).

Simple connectivity measures assume that the non-habitat matrix has no effect on the movement of individuals between patches. In reality, permeability of non-habitat is likely to 
vary across space, based on prevailing habitat features affecting the ability of animals to migrate and disperse; therefore, it is necessary to define characteristics of the landscape that facilitate or oppose dispersal across space (e.g. turtle population structure in relation to roads; Patrick and Gibbs 2010). One approach is to develop connectivity measures specific to the species of interest, because the way in which species perceive the environment may differ dramatically based on features such as body size, crypsis, or thermal suitability.

Consequently, there is no single connectivity index to choose from, but a multitude reflecting the environment and species in question.

The permeability of the landscape to species movements can be assessed using leastcost path analysis. Least-cost path analysis calculates a cost surface based on habitat qualities that impede or facilitate movement of a species (e.g. altitude, high UV, or rivers): the lower the cost, the more likely it is for a species to disperse along this path. Cost surfaces do not take into account other landscape features important to a species, such as habitat patch size. In a study on Florida Scrub Lizards (Sceloporus woodi), least-cost surfaces were generated by classifying habitat types relative to the movement abilities of the lizards, an approach that was a better predictor of genetic variation in the lizards than simple Euclidean distance (Hokit et al. 2010). Similarly, least-cost surfaces have been used to identify road mortality hotspots for four species of turtles in New York State, and inform mitigation strategies (Patrick et al. 2012).

Latest developments in evaluating functional connectivity of landscapes draw on network analysis, a branch of graph theory which analyses flow and connectivity. In the case of landscapes, a network consists of discrete habitat patches ('nodes') connected via links along which dispersal or gene flow occurs. This approach has been applied to New Zealand Grand Skinks, assessing effects of reductions in vegetation matrix quality on connectivity and thus metapopulation dynamics (Harris et al. 2014). 


\subsubsection{Landscape thresholds and conservation management decision-making}

Landscape thresholds, which combine aspects of landscape configuration, composition and connectivity, have become an important tool for defining critical thresholds in resource distribution that would entail significant ecological responses of species. Specifically, habitat loss may reach certain levels, or thresholds, beyond which species occupancy may be compromised due to changes in structural and functional connectivity. Thresholds may be examined at the level of individual species (Betts and Villard 2009), or communities, i.e. through species richness (Radford et al. 2005). Landscape thresholds have been identified for some amphibian species in response to anthropogenic habitat alteration (Popescu and Gibbs 2010), but have not been widely adopted in reptile studies. Because they have the potential to offer specific management recommendations (i.e. retain a specific percentage of a forest habitat within a certain radius from rocky outcrops to ensure population persistence), research linking habitat change to population response deserves further exploration.

\subsubsection{Edge effects}

An important consideration in landscape ecology, in addition to patch size, patch quality and connectivity, is the "edge effect". Edges encompass biotic and abiotic differences, in comparison to core habitat, due to the interaction of two habitat types (Murcia 1995), and often have different environmental conditions, such as temperature or moisture, to which reptiles are particularly sensitive (Lehtinen et al. 2003). The effects of edges in reptiles have proven to be variable, being found to affect community structure in some studies (Lehtinen et al. 2003), but not in others (Dixo and Martins 2008). Edges can be defined in GIS based on habitat boundaries, and edge effects can be investigated, for example, by comparing habitat 
patch size with the length of habitat edges; software such as Fragstats (see Table 22.3) can compute a range of such landscape metrics.

\subsection{GIS for species conservation}

\subsubsection{Modelling and mapping species distributions}

Knowledge of which factors correlate with species presence or abundance is important for defining distribution patterns of species, which consequently influence conservation and management decision. Reptile occurrence and abundance are strongly influenced by vegetation type and structure, soil type, climate, and other environmental factors, the effects of which have often been found to override the influence of habitat patch size and shape (Jellinek et al. 2004, Schutz and Driscoll 2008).

The emergence of GIS has greatly enhanced our ability to quantitatively describe environmental factors with which a species associates and predict species occurrence and abundance. For example, for known occurrence points of a species, we can easily extract climatic variables, elevation, habitat type or soil type (Kearney and Porter 2004). Given the many data gaps that persist in our knowledge of reptile distributions, we can use these correlative variables to predict where species may occur in space or, given scenarios of climate change or land use change, where they may occur in the future; these are ecological niche modelling exercises, which can be addressed using methods such as ensemble species distribution modelling (Araujo and New 2007). For example, Raxworthy et al. (2003) related known occurrence records for Madagascan chameleon species to a suite of spatial data layers describing the ecological landscape, including land cover, a range of variables on precipitation, temperature and cloud cover, and topographical data (e.g. elevation, slope, aspect, flow accumulation and direction). This approach provided informative distribution 
data for the species under study and offers an innovative way for discovering unknown distributional areas of species.

Species' distribution and locality data also aid conservation assessments (e.g., IUCN Red List of Threatened Species), and conservation decision-making. For many smaller-scale landscape studies, these data are often collected during field observations. However, for larger-scale studies, species locality data have traditionally come from georeferenced literature records and museum specimens via online repositories. The availability of large data repositories of species occurrence records, such as the Global Biodiversity Information Faculty (GBIF; http://www.gbif.org/), iNaturalist (http://www.inaturalist.org/) or georeferenced photo records [e.g. Flickr (https://www.flickr.com) or Picasa (https://picasaweb.google.com)] has increased our ability to access and share locality information of species. For example, GBIF records were recently combined with species occurrences published in the literature and expert data to produce an updated atlas of European reptiles and amphibians (Sillero et al. 2014). However, care should be taken when using these data due to quality issues that may affect the accuracy of resulting distribution maps (see section 22.5).

Additionally, spatial tools are increasingly being developed to aid species distribution mapping for conservation. For example, GeoCAT, developed by the Royal Botanic Gardens at Kew, allows users to upload locality data from their own records as well as online databases, calculate range-based measurements for IUCN Red List assessments, and allow output of locality records for further analysis or sharing with collaborators (http://geocat.kew.org; Bachman et al. 2011).

\subsubsection{Landscape ecology for reptile conservation}


Knowledge of species distributions and habitat associations is vital to determine the most appropriate conservation and management actions. Many studies rely heavily on remote sensing and GIS to determine habitat suitability. For example, GIS has been used to determine the most suitable reintroduction sites for species of conservation concern, or to determine sites for assisted translocations (Dade et al. 2014). Although there is much controversy about assisted translocations due to the dangers of introducing species to new environments, some species with poor dispersal ability may rely on this approach for survival, specifically under scenarios of climate change. For example, a composite index of habitat suitability was created to map habitat for the Critically Endangered Swamp Tortoise Pseudemydura umbrina, thus facilitating the conservation decision-making process with the use of spatially-explicit data and GIS (Dade et al. 2014).

Landscape genetics combines landscape ecology with population genetics, investigating the effects of global change on evolutionary processes, patterns of genetic diversity and gene flow (Manel and Holderegger 2013). In essence, landscape genetics correlates spatial heterogeneity of landscapes with gene flow, using a number of methodological approaches, such as Mantel tests, resistance surfaces, and network theory. Mantel tests, for example, relate matrices of genetic distance to matrices of Euclidean distances (e.g. distances between discrete habitat patches). Resistance surfaces assign values of permeability to landscape features, i.e. reflecting the degree to which landscape features impede or enhance gene flow (Spear et al. 2010). For example, genetic variability across a landscape of rocky outcrops was studied in the Ornate Dragon, Ctenophorus ornatus, using Mantel tests. This research determined that there was significant genetic differentiation between discrete rocky outcrop populations and significant effects of isolation across geographic regions (Levy et al. 2013). 
Spatial analyses relying on empirical information on animal movements and habitat associations have been used to inform conservation strategies for mitigating one of the most prevalent threats to reptile population persistence - road mortality (Steen and Gibbs 2004). For example, using analysis of movement at three spatial scales, Beaudry et al. (2008) identified road mortality hotspots for two threatened turtles in North America (Spotted Turtle Clemmys guttata and Blanding's Turtle Emydoidea blandingii), and highlighted the best locations and timing for implementing mitigation strategies. Other studies combined spatial analyses with empirical movement data (i.e. road crossing speed) to identify road mortality risk for Hermann's Tortoises (Testudo hermanni boettgeri; Iosif et al. 2013) and mortality hotspots for turtles (Patrick et al. 2012) across large geographic extents (1000s of km²).

\subsubsection{Macroecology and biogeography for reptile conservation}

When steering global conservation action, broad-scale analyses can help us find answers to some key questions: Where do we best target conservation action (e.g., where are most of our threatened species found)? Where do we best target research to address data gaps (e.g., where are areas of high data deficiency)? Can we maximise conservation outcomes for a large number of species (e.g., are patterns we see congruent between species groups)? The recent global assessment of extinction risk of a random sample of 1,500 reptiles (Böhm et al. 2013) has begun to address some of these questions for reptiles. By overlaying a grid (here, hexagonal grid cells of 7,770 $\mathrm{km}^{2}$ ) onto the aggregated species' distribution and calculating the proportion of species in each grid cell (Figure 22.3), Böhm et al. (2013) identified 1) species richness in the sample to be highest in tropical regions; 2) localised centres of threatened species richness across the globe; and 3) centres of data deficiency.

Patterns of species richness are often used to define hotspots of biodiversity, although these hotspots are generally defined using a restricted number of species groups. Whether or 
not richness patterns between species groups are congruent greatly affects the delineation and effectiveness of any such hotspots. Reptiles have been scarcely addressed in such large-scale analyses. For example, lizard species richness in Australia was found to be generally uncorrelated with that of other vertebrate taxa because different environmental factors were predictors of lizard richness: richness was highest in dry and hot regions (Powney et al. 2010).

\subsection{Spatial statistics: the analysis of spatially-correlated data}

Spatial data are likely to violate data independence assumptions because measurements taken at geographically close locations are generally more alike than measurements taken at geographically distant locations (spatial autocorrelation). The risk of ignoring spatial autocorrelation in the analysis of spatial data is that we may obtain significant results when these are only a reflection of underlying spatial effects (Type I error). There are a number of tools and packages available providing user-friendly options for analysing spatial data, including analysis options in the freely available statistical environment $\mathrm{R}$ or other specialist open-access software (see Table 22.3). However, it is often difficult to decide a priori which analysis method is best because not all spatial methods have been shown to improve inference over non-spatial methods (Bini et al. 2009).

Depending on the question under investigation, spatial autocorrelation can be analysed in a multitude of ways. Most prominent are indices for global spatial autocorrelation (e.g. Moran's $I$ ) and local spatial clustering (K functions, Getis-Ord Local $G$ ), tests of spatial autocorrelation (Mantel and paired Mantel tests), and correlations estimating effective degrees of freedom based on spatial autocorrelation in the data.

Apart from reflecting the degree of spatial autocorrelation in a dataset, analysis of spatial clusters can help us to investigate how a species uses its environment (e.g. analysing 
the placement of burrows). In its simplest form, a univariate $\mathrm{K}$-function, $\mathrm{K}(r)$, of a point pattern is defined as the expected number of points within a distance $r$ of an arbitrary point; these K-functions are considered robust in cases where a point pattern is incomplete (i.e. where there are missing data). Using this method established, for example, that Desert Tortoise (Gopherus agassizii) burrows are aggregated across the landscape at multiple spatial scales and that tortoises are spatially associated with burrows (Duda et al. 2002), suggesting best surveying techniques for this species.

Spatial autocorrelation can be accounted for in advanced modelling techniques through autologistic regression and geographically weighted regression (GWR), or as spatial autocorrelation structures in generalised linear mixed models or generalised least squares models. Autologistic regression models provide an extension to logistic (presence/absence) models by including an auto-covariate to account for spatial autocorrelation within the data. For example, autologistic regression was used to investigate patterns of turtle nest predation (Kinosternon subrubrum, Pseudemys concinna floridana, and Trachemys scripta), where it was assumed that a predator preying on one nest was more likely to search for and find neighbouring nests (Burke et al. 1998). GWR considers local spatial relationships by creating a local regression equation for each data point, thus allowing the relationship between predictor and response variables to vary across space. For example, Powney et al. (2010) used GWR to explore geographical patterns of lizard species richness in Australia, showing that richness is predicted by different environmental factors than in other vertebrates.

\subsection{Shortcomings and future directions}

Despite the many research opportunities they provide, GIS and spatial data come with a set of limitations. It is important to be aware of these in order to produce robust analyses and the best possible outcomes for conservation: 
1. Although technology is rapidly advancing, data availability is still somewhat lagging behind. This is especially true for data that capture rapidly occurring landscape change. Updating large-scale global data sets at high resolutions is time-consuming, and there is a considerable temporal data gap in many spatial data layers (e.g. updated every 10 years; or data for many years are aggregated into a single data layer).

2. Because researchers are looking for the most up-to-date information, many analyse remotely-sensed data (e.g. Landsat) by implementing their own classification system. Consequently, there is a multitude of differently classified data available, often designed to best represent certain study species, which limits comparability between studies.

3. For many herpetologists, remotely-sensed data are often still at too coarse a scale to allow the accuracy needed to depict habitat types or habitat change over time, and relate this to specific reptile populations. Similarly, global databases such as GBIF (see section 22.3.1) often include spatially and taxonomically inaccurate data; therefore, great care needs to be taken when using these data.

4. Spatial data can only provide part of the puzzle of what determines reptile distributions and abundance. There are other important factors for which it is more difficult to obtain spatial data or for which spatial data do not exist (e.g. inter-specific interactions, certain threat processes such as overharvesting). In addition, it is important that field data underpin or validate any model approaches, both for species occurrences and environmental data related to these occurrences.

Many of these limitations are likely to be overcome or at least minimised with technological advances in the gathering and processing of spatial data. Technological advances have recently led to the first use of remotely-sensed data from airborne LiDAR (Light Detection and Ranging) sensors in ecological studies of reptiles, with the development 
of digital vegetation surfaces based on satellite data with a pixel size $<1 \mathrm{~m}$ resolution (Sillero and Goncalves-Seco 2014).

Reptiles are still widely overlooked in conservation decision-making unless they are directly targeted by endangered species legislation (e.g. Endangered Species Act (ESA) in the US, Species at Risk Act (SARA) in Canada, Habitats Directive in Europe). Since population data for status assessments of many species are often lacking, many conservation assessments derive from knowledge of reptile species distributions. More and more data are becoming available on reptile distribution, not the least through the work of initiatives such as the IUCN Global Reptile Assessment (https://www.iucn.org/about/union/secretariat/offices/usa/about_usa/bau/) and collaborative efforts to map the distribution of all reptiles (http://www.gardinitiative.org/). Both initiatives are set to produce large spatial datasets of reptile distributions, which together with the everincreasing availability of large-scale environmental and threat data will further aid future conservation assessments. For example, reptile distribution maps in conjunction with correlates of extinction risk will allow us to be more predictive about extinction risk and to provide more timely assessments for species. With increased research attention on speciesindependent threat mapping (e.g. Murray et al. 2014), future assessments of extinction risk may be increasingly founded on objective spatial data on threat processes (e.g. forest loss (Hansen et al. 2013), climate change (IPCC 2013)).

GIS and spatial analyses for studying reptile ecology and conservation are increasing, but it is paramount that GIS literacy and proficiency is increased through collaborative efforts and capacity building. Since conservation decisions are often based on spatial data (i.e. species and threat distributions), there is a dire need to better understand how reptiles interact with their environment, and how landscape or climatic changes are likely to affect reptile distributions locally, regionally, and globally. 


\subsection{References}

Araújo, M.B., and New, M. (2007). Ensemble forecasting of species distributions. Trends in Ecology and Evolution, 22, 42-47.

Bachman, S., Moat, J., Hill, A.W., de la Torre, J., et al. (2011). Supporting Red List threat assessments with GeoCAT: geospatial conservation assessment tool. ZooKeys, 150, $117-26$.

Beaudry, F., de Maynadier, P.G., and Hunter, M.L. (2008). Identifying road mortality threat at multiple spatial scales for semi-aquatic turtles. Biological Conservation, 141, 2550-63.

Betts, M.G., and Villard, M.-A. (2009). Landscape thresholds in species occurrence as quantitative targets in forest management: generality in space and time? In M.-A. Villard, and B.G. Jonsson (eds). Setting conservation targets for managed forest landscapes, pp. 185-206. Cambridge University Press, Cambridge, UK.

Bini, L.M., Diniz, J.A.F., Rangel, T.F.L.V.B., Akre, T.S.B., et al. (2009). Coefficient shifts in geographical ecology: an empirical evaluation of spatial and non-spatial regression. Ecography, 32, 193-204.

Böhm, M., Collen, B., Baillie, J.E.M., Bowles, P., et al. (2013). The conservation status of the world's reptiles. Biological Conservation, 157, 372-85.

Burke, V.J., Rathbun, S.L., Bodie, J.R., and Gibbons, J.W. (1998). Effect of density on predation rate for turtle nests in a complex landscape. Oikos, 83, 3-11.

Dade, M.C., Pauli, N., and Mitchell, N.J. (2014). Mapping a new future: using spatial multiple criteria analysis to identify novel habitats for assisted colonization of endangered species. Animal Conservation, 17, 4-17.

Dixo, M., and Martins, M. (2008). Are leaf-litter frogs and lizards affected by edge effects due to forest fragmentation in Brazilian Atlantic forest? Journal of Tropical Ecology, 24, 551-54.

Duda, J.J., Krzysik, A.J., and Meloche, J.M. (2002). Spatial organization of desert tortoises and their burrows at a landscape scale. Chelonian Conservation and Biology, 4, 38797.

Gebauer, K., Dickinson, K.J.M., Whigham, P.A., and Seddon, P.J. (2013). Matrix matters: differences of grand skink metapopulation parameters in native tussock grasslands and exotic pasture grasslands. PLoS One, 8, e76076. 
Hansen, M.C., Potapov, P.V., Moore, R., Hancher, M., et al. (2013). High-Resolution Global Maps of 21st-Century Forest Cover Change. Science, 342, 850-53.

Hanski, I. (1999). Metapopulation Ecology. Oxford University Press, Oxford, UK.

Harris, K.M., Dickinson, K.J.M., and Whigham, P.A. (2014). Functional connectivity and matrix quality: network analysis for a critically endangered New Zealand lizard. Landscape Ecology, 29, 41-53.

Hokit, D.G., Ascunce, M., Ernst, J., Branch, L.C., et al. (2010). Ecological metrics predict connectivity better than geographic distance. Conservation Genetics, 11, 149-59.

Iosif, R., Rozylowicz, L., and Popescu, V.D. (2013). Modeling road mortality hotspots for Eastern Hermann's tortoise in Romania. Amphibia-Reptilia, 34, 163-72.

IPCC (2013). Climate change 2013: the physical science basis. In T.F. Stocker, D. Qin, G.-K. Plattner, M.M.B. Tignor, S.K. Allen, J. Boschung, A. Nauels, Y. Xia, V. Bex, and P.M. Midgley (eds). Working Group I Contribution to the Fifth Assessment Report of the Intergovernmental Panel on Climate Change, p. 203. Cambridge University Press, Cambridge, UK.

Jellinek, S., Driscoll, D.A., and Kirkpatrick, J.B. (2004). Environmental and vegetation variables have a greater influence than habitat fragmentation in structuring lizard communities in remnant urban bushland. Austral Ecology, 29, 294-304.

Kearney, M., and Porter, W.P. (2004). Mapping the fundamental niche: physiology, climate, and the distribution of a nocturnal lizard. Ecology, 85, 3119-31.

Lehtinen, R.M., Ramanamanjato, J., and Raveloarison, J.G. (2003). Edge effects and extinction proneness in a herpetofauna from Madagascar. Biodiversity and Conservation, 12, 1357-70.

Levy, E., Tomkins, J.L., Lebas, N.R., and Kennington, W.J. (2013). Contrasting effects of landscape features on genetic structure in different geographic regions in the ornate dragon lizard, Ctenophorus ornatus. Molecular Ecology, 22, 3904-15.

Lindenmayer, D., Hobbs, R.J., Montague-Drake, R., Alexandra, J., et al. (2008). A checklist for ecological management of landscapes for conservation. Ecology Letters, 11, 7891.

Manel, S., and Holderegger, R. (2013). Ten years of landscpe genetics. Trends in Ecology and Evolution, 28, 614-21.

Murcia, C. (1995). Edge effects in fragmented forest: implication for conservation. Trends in Ecology \& Evolution, 10, 58-62. 
Murray, K.A., Verde Arregoitia, L.D., Davidson, A., Di Marco, M., et al. (2014). Threat to the point: improving the value of comparative extinction risk analysis for conservation action. Global Change Biology, 20, 483-94.

Patrick, D., and Gibbs, J. (2010). Population structure and movements of freshwater turtles across a road-density gradient. Landscape Ecology, 25, 791-801.

Patrick, D.A., Gibbs, J.P., Popescu, V.D., and Nelson, D.A. (2012). Multi-scale habitatresistance models for predicting road mortality "hotspots" for turtles and amphibians. Herpetological Conservation and Biology, 7, 407-26.

Popescu, V.D., and Gibbs, J.P. (2010). Landscape ecology and GIS methods. In C.K. Dodd, Jr. (ed). Amphibian Ecology and Conservation: A Handbook of Techniques, pp. 339360. Oxford University Press, Oxford, UK.

Powney, G.D., Grenyer, R., Orme, C.D.L., Owens, I.P.F., et al. (2010). Hot, dry and different: Australian lizard richness is unlike that of mammals, amphibians and birds. Global Ecology and Biogeography, 19, 386-96.

Radford, J.Q., Bennett, A.F., and Cheers, G.J. (2005) Landscape-level thresholds of habitat cover for woodland-dependent birds. Biological Conservation, 125, 317-337.

Raxworthy, C.J., Martinez-Meyer, E., Horning, N., Nussbaum, R.A., et al. (2003). Predicting distributions of known and unknown reptile species in Madagascar. Nature, 426, 83741.

Schutz, A.J., and Driscoll, D.A. (2008). Common reptiles unaffected by connectivity or condition in a fragmented farming landscape. Austral Ecology, 33, 641-52.

Sillero, N., and Tarroso, P. (2010). Free GIS for herpetologists: free data sources on Internet and comparison analysis of proprietary and free/open source software. Acta Herpetologica, 5, 63-85.

Sillero, N., and Goncalves-Seco, L. (2014). Spatial structure analysis of a reptile community with airborne LiDAR data. International Journal of Geographical Information Science, 28, 1709-22.

Sillero, N., Campos, J., Bonardi, A., Corti, C., et al. (2014). Updated distribution and biogeography of amphibians and reptiles of Europe. Amphibia-Reptilia, 35, 1-31.

Spear, S.F., Balkenhol, N., Fortin, M.J., McRae, B.H., and Scribner, K. (2010). Use of resistance surfaces for landscape genetic studies: considerations for parameterization and analysis. Molecular Ecology, 19, 3576-91.

Steen, D.A., and Gibbs, J.P. (2004). Effects of roads on the structure of freshwater turtle populations. Conservation Biology, 18, 1143-48. 
Stellatelli, O.A., Vega, L.E., Block, C., and Cruz, F.B. (2013). Effects of tree invasion on the habitat use of sand lizards. Herpetologica, 69, 455-65.

Thomas, C.D., Cameron, A., Green, R.E., Bakkenes, M., et al. (2004). Extinction risk from climate change. Nature, 427, 145-48.

Wiens, J.A., Stenseth, N.C., Horne, B.V., and Ims, R.A. (1993). Ecological mechanisms and landscape ecology. Oikos, 66, 369-80.

\section{Tables and Figures}

Table 22.1 Popular commercial and open-source GIS software packages. Also consult freegis.org and opensourcegis.org.

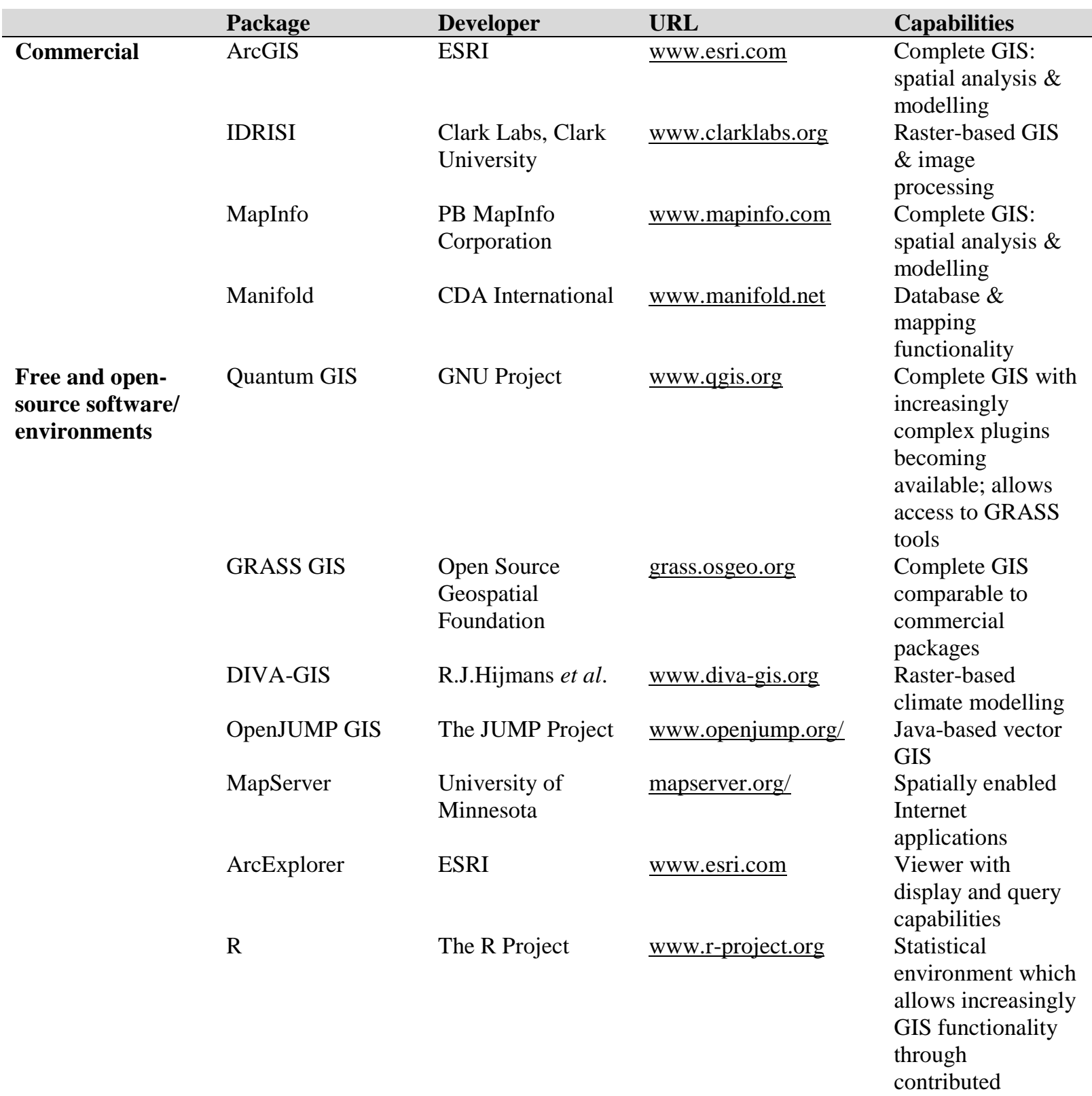


Table 22.2 Global and regional open-source data layers and providers to get started with spatial analysis at the landscape and macroecological level. This is by no means an exhaustive list and web searches are likely to uncover many more data sources and GIS resources.

\begin{tabular}{|c|c|c|c|c|}
\hline Data type & Variables/layers & Resolution & Timeframe & URL \\
\hline \multirow[t]{6}{*}{ Geographical } & World maps and country outlines & NA & NA & https://www.freevectormaps.com/world-maps \\
\hline & Hydrological variables & 3 arcseconds & & http://hydrosheds.cr.usgs.gov/hydro.php \\
\hline & & 15 arcseconds & & \\
\hline & & 30 arcseconds & & \\
\hline & & 5 arcminutes & & \\
\hline & Protected areas & NA & Continuously updated & http://www.protectedplanet.net/ \\
\hline \multirow[t]{6}{*}{ Climatic } & Temperature (monthly min, max, & 10 arcminutes & Past, current, future & http://www.worldclim.org/ \\
\hline & mean) & 5 arcminutes & & \\
\hline & Precipitation & 2.5 arcminutes & & \\
\hline & Bioclimatic variables & 30 arcseconds & & \\
\hline & Climatic observations and scenarios & Various & Various & http://www.ipcc-data.org/ \\
\hline & Atmospheric and oceanic variables & Various & Past, current, future & http://www.ncdc.noaa.gov/ \\
\hline \multirow[t]{5}{*}{ Topological } & Altitude & 30 arcseconds & NA & http://earthexplorer.usgs.gov/ \\
\hline & & 10 arcminutes & & http://www.worldclim.org/ \\
\hline & & 5 arcminutes & & \\
\hline & & 2.5 arcminutes & & \\
\hline & & 30 arcseconds & & \\
\hline \multirow[t]{9}{*}{ Biological } & Net primary productivity (NPP); & $\begin{array}{l}0.25 \text { decimal } \\
\text { degrees }\end{array}$ & 1995 & http://sedac.ciesin.columbia.edu \\
\hline & $\begin{array}{l}\text { Global Mangrove Forest } \\
\text { Distributions }\end{array}$ & $30 \mathrm{~m}$ & 2000 & http://sedac.ciesin.columbia.edu \\
\hline & $\begin{array}{l}\text { Ecoregions: terrestrial, freshwater, } \\
\text { marine }\end{array}$ & NA & 2001 & $\begin{array}{l}\text { https://www.worldwildlife.org/publications/terr } \\
\text { estrial-ecoregions-of-the-world }\end{array}$ \\
\hline & & & 2013 & http://www.feow.org/downloads \\
\hline & & & 2007 & $\begin{array}{l}\text { http://www.comlmaps.org/how-to/layers-and- } \\
\text { resources/boundaries/marine-ecoregions-of-the- } \\
\text { world }\end{array}$ \\
\hline & Land cover & $\begin{array}{l}30 \text { arcseconds }(\sim 1 \\
\mathrm{km})\end{array}$ & $1992-2000$ consensus & http://www.earthenv.org/landcover.html \\
\hline & & $1 \mathrm{~km}$ & $1992 / 1993$ & http://edc2.usgs.gov/glcc/glcc.php \\
\hline & & $1 \mathrm{~km}$ & 2000 & $\begin{array}{l}\text { http://bioval.jrc.ec.europa.eu/products/glc2000/ } \\
\text { products.php }\end{array}$ \\
\hline & & $500 \mathrm{~m}$ & 2005 & $\begin{array}{l}\text { https://lpdaac.usgs.gov/products/modis_product } \\
\text { s_table/mcd12q1 }\end{array}$ \\
\hline
\end{tabular}




\section{Pressures \& threats}

Species data

Human population density

Accessibility

Human appropriation of NPP

(HANPP)

Tree cover \& change

Millennium Ecosystem scenarios

Species distributions
$300 \mathrm{~m}$

30 arcseconds

0.25 decimal

degrees

30 metres

Various

NA
2004-2006

$1990,1995,2000$

2000

1995

2000-present

1995-2100

2010 and updated periodically

2015 http://due.esrin.esa.int/page_globcover.php

http://sedac.ciesin.columbia.edu

http://bioval.jrc.ec.europa.eu/products/gam/dow nload.htm

http://sedac.ciesin.columbia.edu

http://data.globalforestwatch.org/

http://sedac.ciesin.columbia.edu/data/collection/

ma

http://www.iucnredlist.org/technical-

documents/spatial-data

http://www.gardinitiative.org/ 
Table 22.3 Spatial statistics functionality in commonly-used GIS software (including QGIS plugins, see https://plugins.qgis.org) and other useful spatial statistics software applications, including relevant libraries in $\mathrm{R}$.

\begin{tabular}{|c|c|c|}
\hline Functionality & Description & Package(s) \\
\hline \multirow[t]{3}{*}{$\begin{array}{l}\text { Data extraction/ } \\
\text { manipulation }\end{array}$} & $\begin{array}{l}\text { Manipulation of spatial features (e.g. clip, } \\
\text { intersect, union, buffer); data extraction from } \\
\text { raster data e.g. Zonal Statistics }\end{array}$ & $\begin{array}{l}\text { ArcGIS, Quantum GIS (QGIS), Geospatial } \\
\text { Modelling Environment, rgeos (R), raster (R) }\end{array}$ \\
\hline & $\begin{array}{l}\text { Counting points in polygons; generating } \\
\text { random points/shapes }\end{array}$ & Geospatial Modelling Environment \\
\hline & $\begin{array}{l}\text { Sampling of polygon attributes and raster } \\
\text { values }\end{array}$ & Point Sampling Tool (QGIS) \\
\hline Spatial models & $\begin{array}{l}\text { Spatial and non-spatial relationships } \\
\text { (regressions), spatial models (e.g. kriging) }\end{array}$ & $\begin{array}{l}\text { ArcGIS, Spatial Analysis in Macroecology } \\
(\mathrm{SAM})^{1}, \text { raster }(\mathrm{R})\end{array}$ \\
\hline \multirow[t]{3}{*}{ Analyzing spatial patterns } & $\begin{array}{l}\text { Nearest neighbour analysis \& statistics, point } \\
\text { distances }\end{array}$ & ArcGIS, QGIS, Fragstats², rgeos (R) \\
\hline & $\begin{array}{l}\text { Clustering, spatial autocorrelation, Ripley's } \\
\text { K-function }\end{array}$ & $\begin{array}{l}\text { ArcGIS, Spatial Analysis in Macroecology } \\
(\mathrm{SAM})^{1}, \text { spdep }(\mathrm{R}), \text { splancs }(\mathrm{R})\end{array}$ \\
\hline & $\begin{array}{l}\text { Patch-based metrics (e.g. edge length, patch } \\
\text { size, isolation, edge contrast etc.) }\end{array}$ & Fragstats $^{2}$ \\
\hline Mapping clusters & $\begin{array}{l}\text { Identification of significant hot- and coldspots } \\
\text { and spatial outliers }\end{array}$ & ArcGIS \\
\hline $\begin{array}{l}\text { Measuring geographic } \\
\text { distributions }\end{array}$ & $\begin{array}{l}\text { Distributional characteristics, such as centre, } \\
\text { compactness, orientation }\end{array}$ & ArcGIS \\
\hline \multirow[t]{2}{*}{$\begin{array}{l}\text { Animal movement } \\
\text { analysis \& networks }\end{array}$} & Minimum convex polygons & $\begin{array}{l}\text { QGIS, AniMove for QGIS, rgeos (R), } \\
\text { adehabitat }(\mathrm{R})\end{array}$ \\
\hline & $\begin{array}{l}\text { Movement path analysis, least cost path } \\
\text { analysis, network analysis }\end{array}$ & ArcGIS, AniMove for QGIS, igraph (R) \\
\hline Land cover analysis & $\begin{array}{l}\text { Calculation of metrics from raster and vector } \\
\text { layers; overlays }\end{array}$ & LecoS: Landscape Ecology Statistics \\
\hline Habitat analyses & Habitat preference, etc. & adehabitat $(\mathrm{R})$ \\
\hline $\begin{array}{l}\text { Interface to the Global } \\
\text { Biodiversity Information } \\
\text { Facility (GBIF) }\end{array}$ & $\begin{array}{l}\text { Searching for and retrieving species } \\
\text { occurrence records directly from GBIF }\end{array}$ & $\operatorname{rgbif}(\mathrm{R})$ \\
\hline
\end{tabular}




\section{Figure legends}

Figure 22.1. Number of journal articles published on the topics of landscape ecology, macroecology and GIS-based studies, by vertebrate taxon group. (Source: Thomson Reuters Web of Science; accessed 25 April 2015).

Figure 22.2. Top: different types of vector data (points, lines, polygons) and raster data overlaid onto each other, showing locality point data (black dots) for an imaginary species collected along rivers (line vector data) in the border region of Brazil and Bolivia (thick black line is the polygon outline, with each country being represented by a polygon). The background shading depicts elevation (raster data), while the grey lines are ecoregion boundaries (again a polygon layer). For example, the ecoregion shaded in darker grey on the right is the Pantanal. See Table 22.2 for commonly used data sources available online. Bottom: example of an attribute table showing data collected for each species locality data point. In this example, each line represents a single point.

Figure 22.3. Global terrestrial and freshwater species richness distributions of a sampled reptile assessment (Böhm et al. 2013): (A) species richness of all species in sample $(N=1,484)$; (B) Distribution of threatened (CR, EN, VU) species in the sample $(N=219)$; (C) Distribution of Data Deficient species in the sample $(N=288)$. Updated from maps shown in Böhm et al. (2013) to reflect latest Red List category changes in the data. All maps show number of species and proportion of species in sample per grid cell. 
Figure 22.1

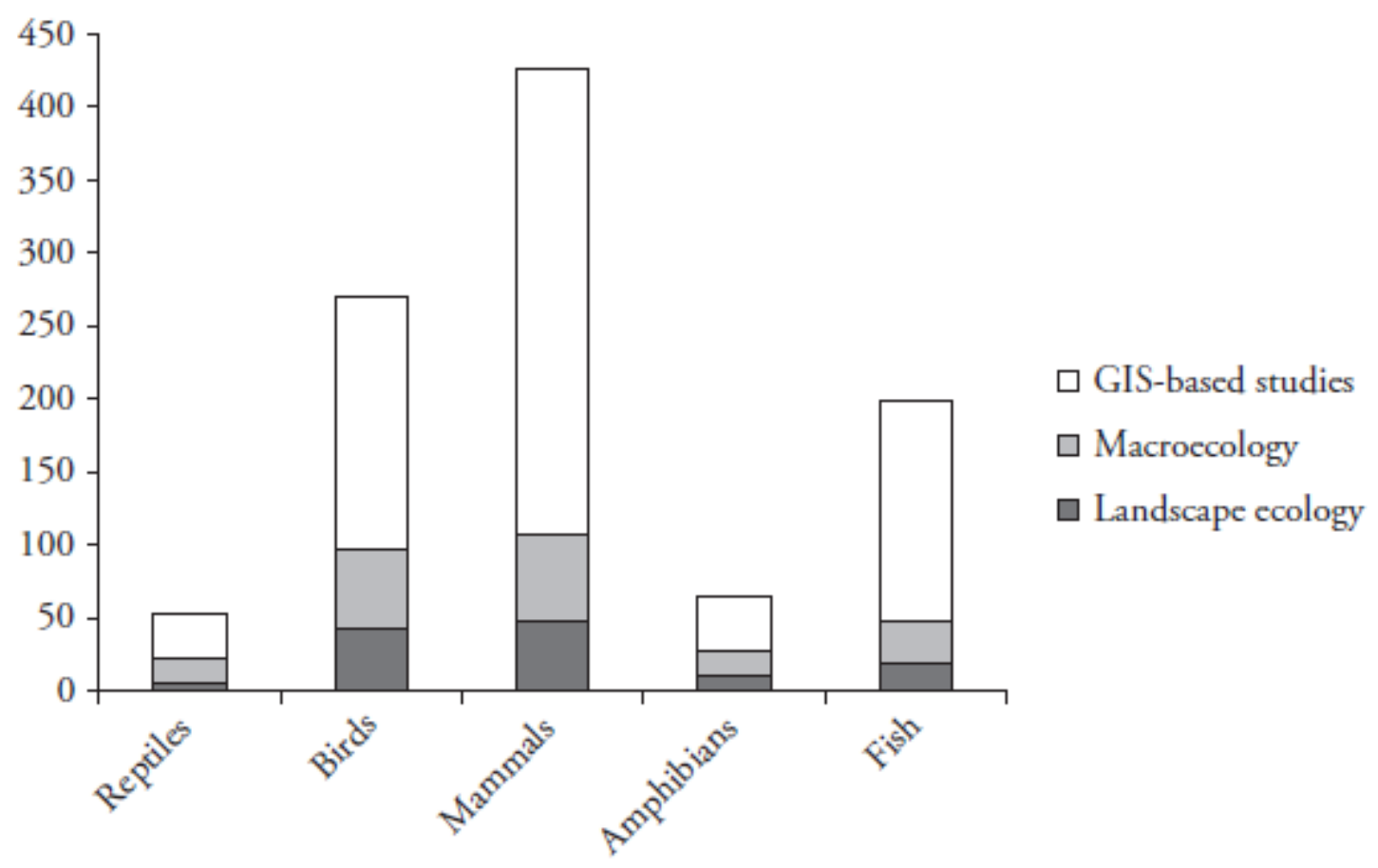


Figure 22.2

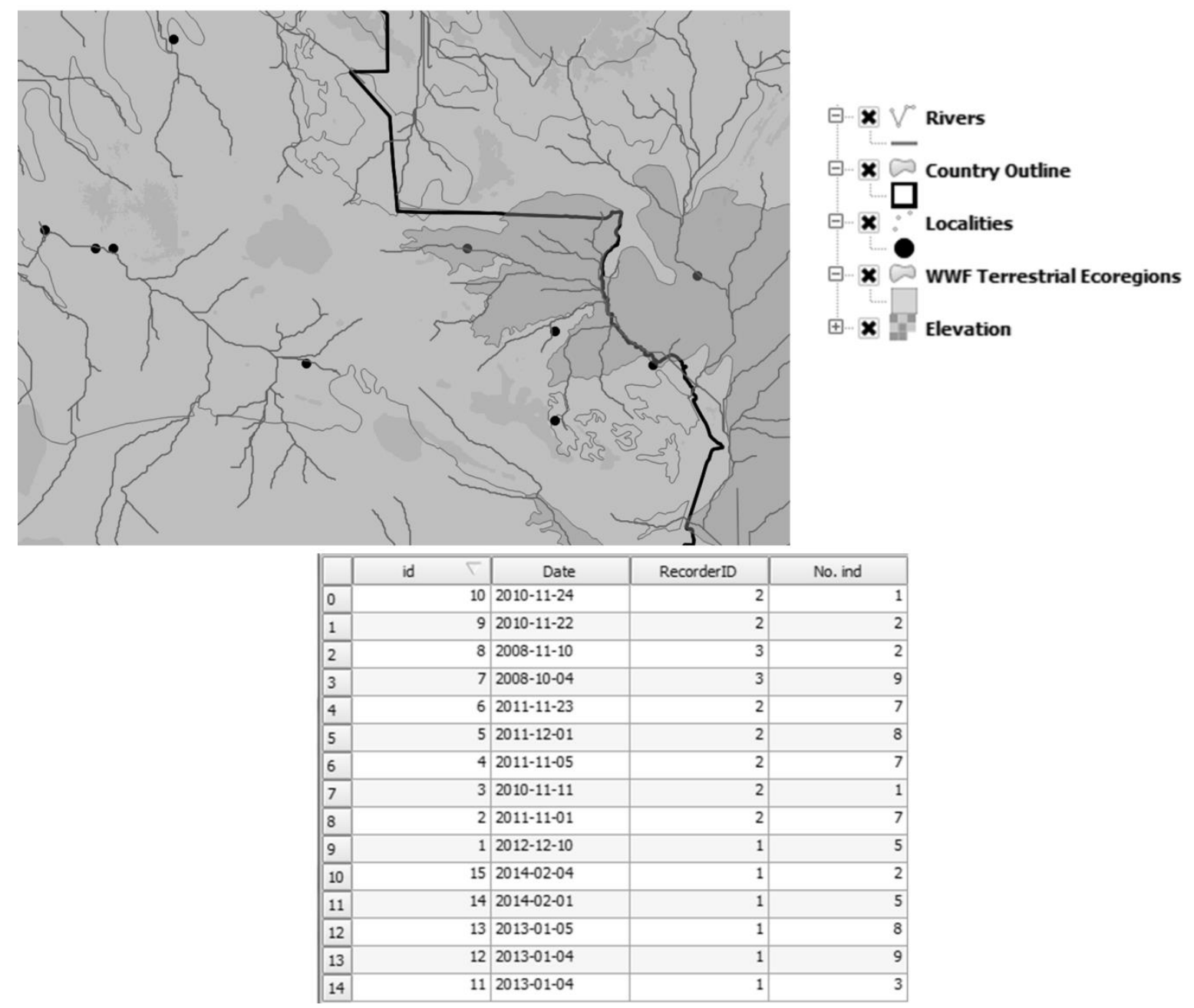


Figure 22.3

(a)

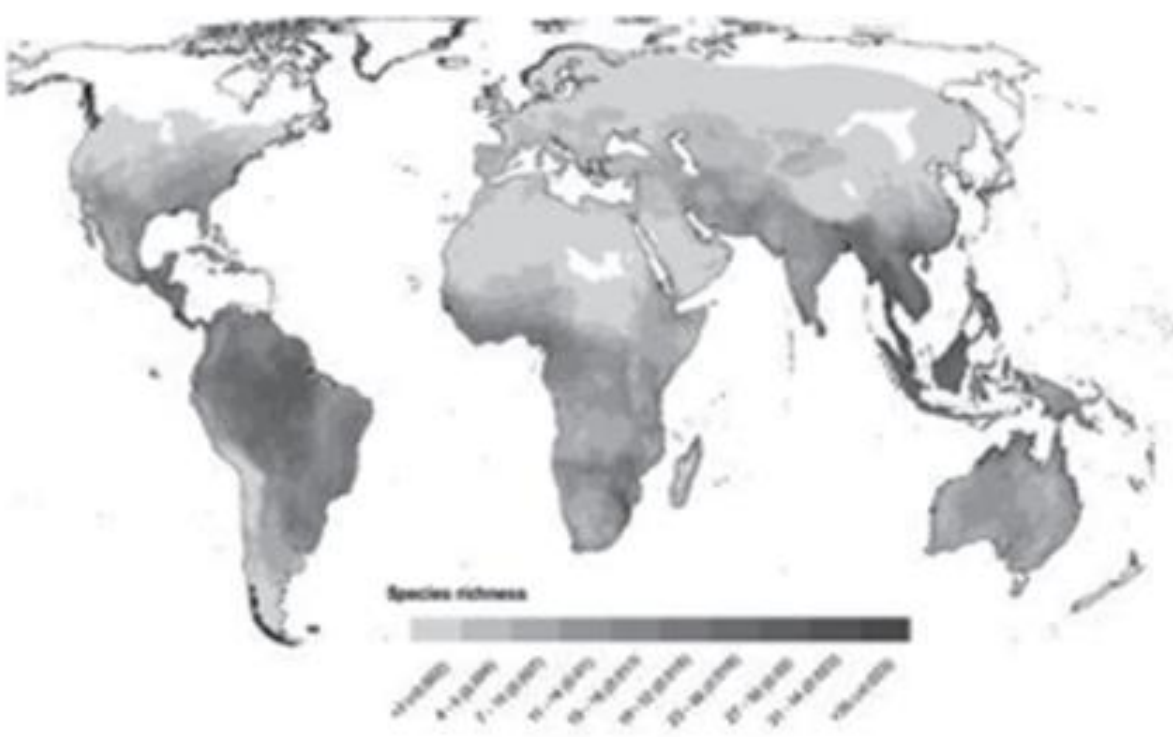

(b)

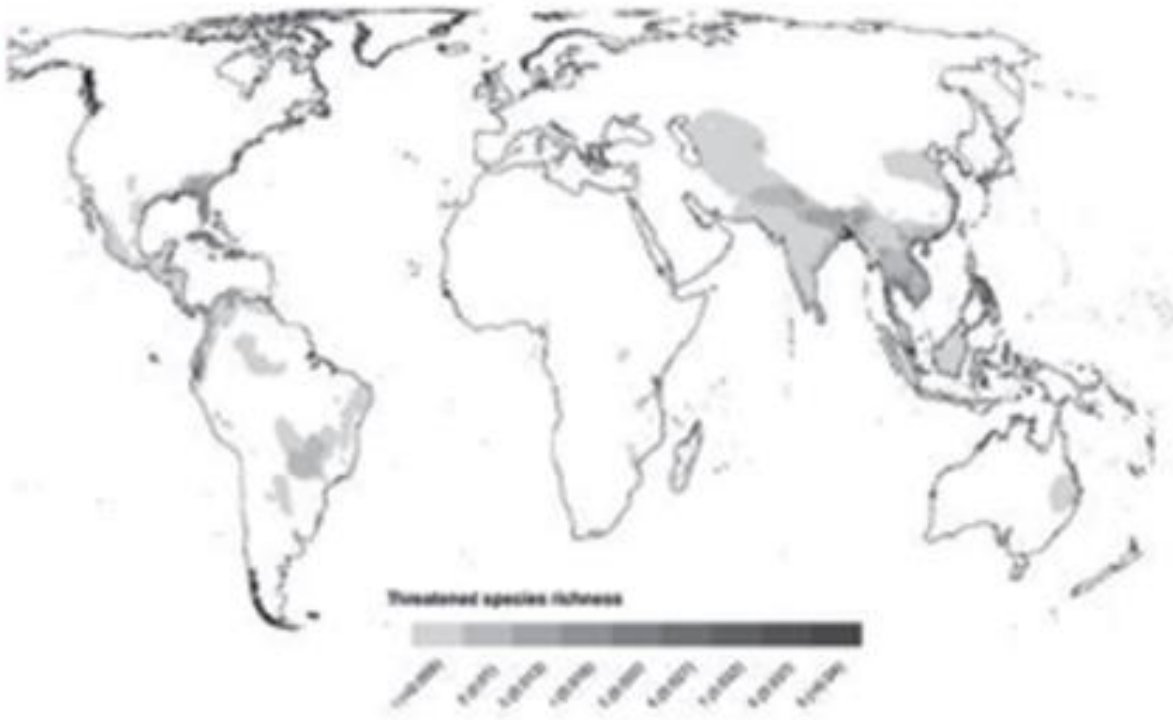

(c)

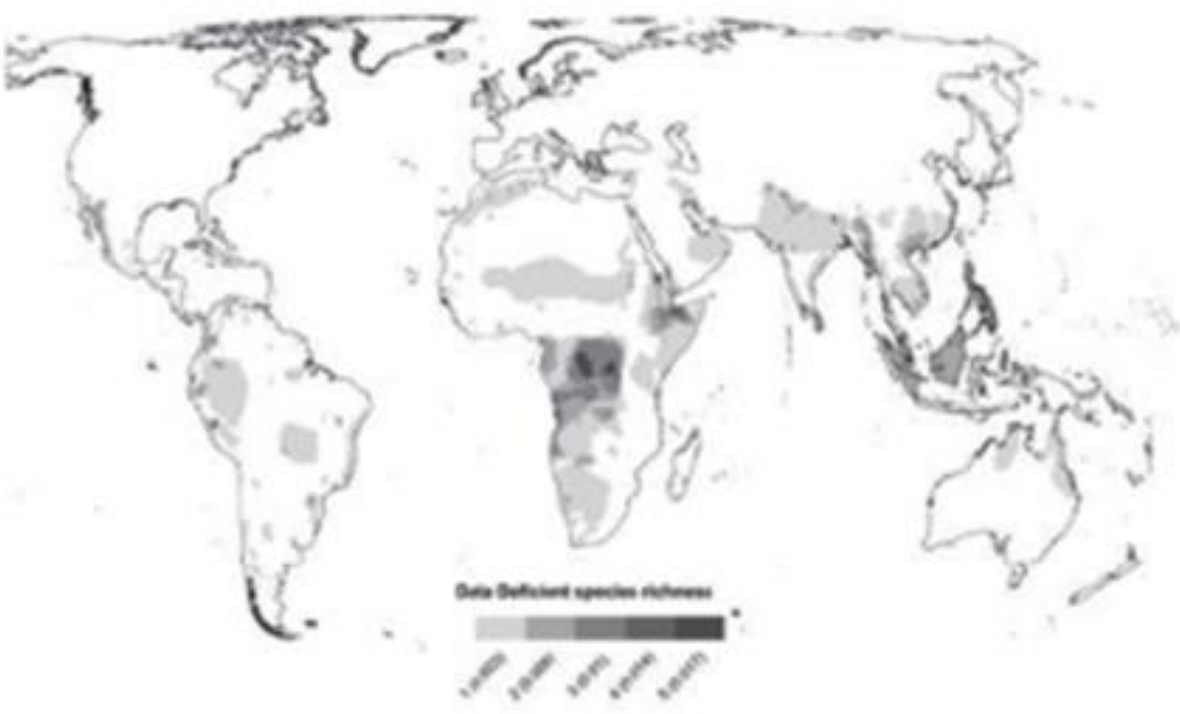

